\title{
A Novel Technique in Collecting Biopsy in Arthroscopy
}

\author{
Sivaraman Balasubramanian ${ }^{1}$, Dinesh Loganathan ${ }^{2}$, Venkataraman Manian ${ }^{3}$, Rahul Vijay Gusain ${ }^{4}$, Bobby Mathiyarasu ${ }^{5}$
}

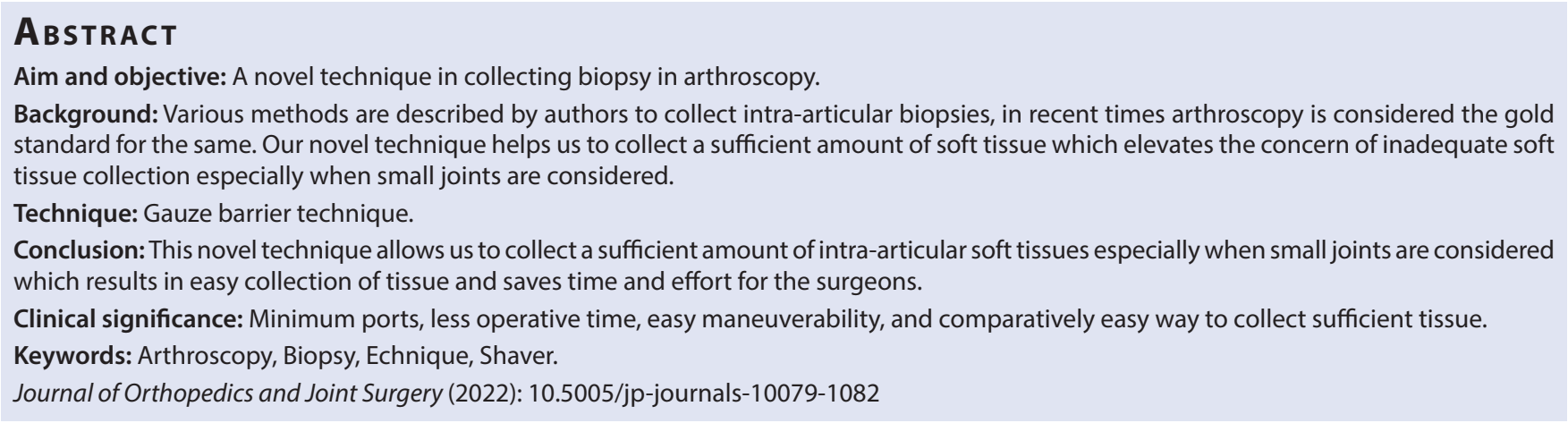

\section{BACKGROUND}

Arthroscopic biopsy has been evolving over a while and is now considered a gold standard to diagnose joint pathologies. Arthroscopy has been proven to cause less morbidity in collecting biopsy when compared to open arthrotomy, it can be used in big as well as small joints. Drawbacks for the same being a learning curve, time consuming, and in many instances loss of tissue or collection of inadequate tissue samples when it comes to small joints. In our novel technique, we believe that time, manpower, and concern to collect adequate biopsy will be elevated.

\section{TECHNIQUe}

Here, we introduce a technique that results in more tissue collection for biopsy when it comes to small joints, for example ankle and wrist. In our technique, we keep a gauze between the suction tube and the suction outlet of the motorized shaver. As the shaver is used over the tissue of interest, the tissue bits get collected in the gauze as it is been sucked resulting in more tissue for the biopsy. It saves operating time by alleviating the repetitive need for usage of hand instruments in collecting the biopsy sample. It also reduces the loss of tissue in the joint space and portal tracts. Our techniques also help in limiting the number of ports to two for the majority of the cases. Figures 1 and 2 show placement of the gauze, and Figure 3 shows the collection of the tissue in the gauze.

\section{Discussion}

Blind biopsy needles like Parker and Pearson needle used a small gauze needle, by this method, an incision is made and the joint capsule is open to retaining the specimen. ${ }^{1}$ This technique may require multiple sessions and histology analysis is only obtained in $61-85 \% .^{2-4}$ Another method in which retrograde forceps ((Retroforceps; Karl Storz, Tuttlingen, Germany) is used in which the forceps is introduced in the joint and suction is applied with a syringe, the fluid is sent for the analysis and when the forceps is pulled back the surgeons feels for the resistance of the capsule and
${ }^{1}$ Department of Orthopaedics, Chettinad Health City, Chennai, Tamil Nadu, India

2,3 ${ }^{2}$ epartment of Orthopaedics, Chettinad Superspeciality Hospital, Chennai, Tamil Nadu, India

${ }^{4}$ Department of Orthopaedics, Chettinad Hospital and Research Institute, Chennai, Tamil Nadu, India

${ }^{5}$ Department of Gynaecology, Apollo Hospital, Chennai, Tamil Nadu, India

Corresponding Author: Sivaraman Balasubramanian, Department of Orthopaedics, Chettinad Health City, Chennai, Tamil Nadu, India, Phone: +91 9500004551, e-mail: Drbsiva@gmail.com

How to cite this article: Balasubramanian S, Loganathan D, Manian $\mathrm{V}$, et al. A Novel Technique in Collecting Biopsy in Arthroscopy. J Orth Joint Surg 2022;4(1):47-48.

Source of support: Nil

Conflict of interest: None

specimen is obtained. ${ }^{5}$ Based on a survey of 15,682 procedures, the most common complications of arthroscopic synovial biopsies performed by rheumatologists are haemarthrosis in $0.9 \%$ and DVT in $0.2 \%$ of patients. Joint infection, wound infection, and neurological damage occur in $0.1 \%, 0.1 \%$, and $0.02 \%$, respectively. ${ }^{6}$ Obtaining adequate specimens in the first attempt has to be considered our main priority to decrease morbidity. In our novel technique of using a gauze barrier, we ensure that along with collected specimens from the forceps or motorized shaver we can collect an adequate quantity of specimen for analysis from small or large joints more efficiently and reduce the chances of the same procedure again in the future.

\section{CONCLUSION}

This novel technique allows us to collect a sufficient amount of intra-articular soft tissues especially when small joints are considered which results in easy collection of tissue and saves time and effort for the surgeons. 


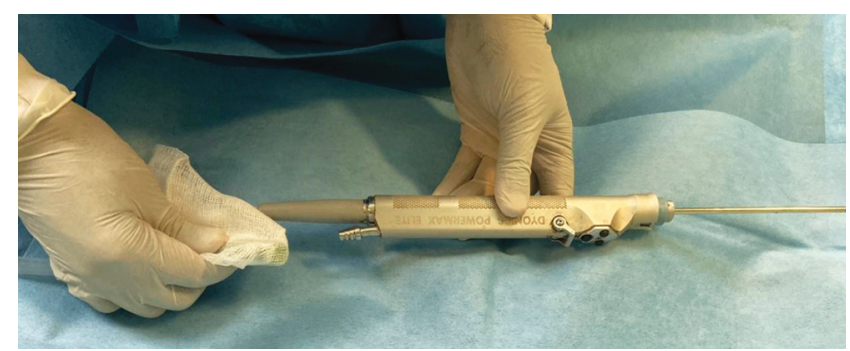

Fig. 1: Gauze placement between suction cannula and motorized shaver

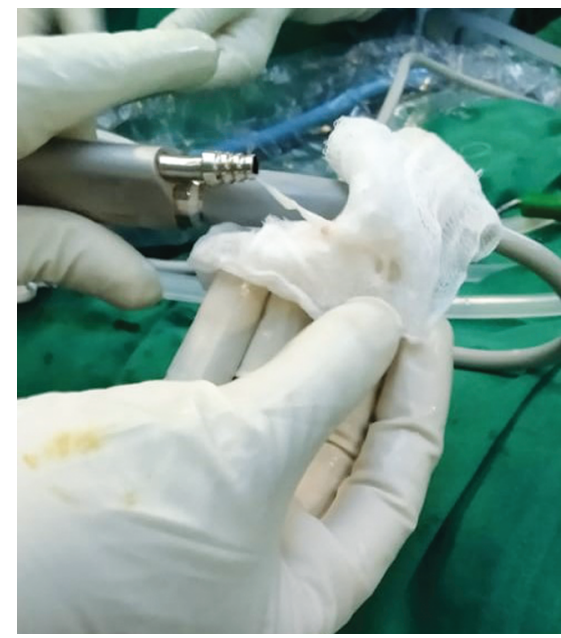

Fig. 3: Collection of the tissue In the gauze piece

\section{Clinical Significance}

With only two ports needed to complete the procedures whether small or large joints, which helps in comparatively less operative time and easy maneuverability resulting in saving manpower as well as operative time. Fewer chances of post-operative infections which is usually a case when more ports are used especially in small joints.

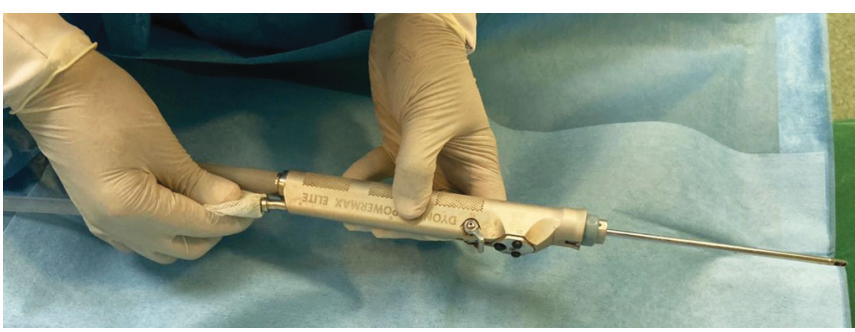

Fig. 2: Gauze placement between suction cannula and motorized shaver

This simple technique is very useful in obtaining adequate synovial tissue from representative areas under direct vision. Not only it helps in obtaining tissues for histopathology but can also be therapeutic in patients where synovectomy can be done simultaneously. Being a day care proceduret is very cost effective.

\section{References}

1. Parker RH, Pearson CM. A simplified synovial biopsy needle. Arthritis Rheum 1963 April;6(2):172-176. DOI: 10.1002/art. 1780060209

2. Venkataraman M, Sathyadharan P. Role of needle synovial biopsy in joint diseases. J Evol Med Dent Sci 2015 Jun 1;4(44):7626-7635. DOI: 10.14260/jemds/2015/1107

3. Gerlag D, Tak PP. Synovial biopsy. Best Pract Res Clinl Rheumatol 2005 Jun 1;19(3):387-400. DOI: 10.1016/j.berh.2005.01.005

4. Humby F, Romão VC, Manzo A, et al. A multicenter retrospective analysis evaluating performance of synovial biopsy techniques in patients with inflammatory arthritis: arthroscopic versus ultrasoundguided versus blind needle biopsy. Arthritis Rheumatol 2018 May;70(5):702-10. DOI: 10.1002/art.40433

5. Hügle T, Leumann A, Pagenstert G, et al. Retrograde synovial biopsy of the knee joint using a novel biopsy forceps. Arthrosc Tech 2014 Jun;3(3):e317-e319.

6. Armstrong RW, Bolding F, Joseph R. Septic arthritis following arthroscopy: clinical syndromes and analysis of risk factors. Arthroscopy: J Arthrosc Relat Surg 1992 Jun 1;8(2):213-23. DOI: 10.1016/0749-8063(92)90039-e 